\title{
РАЗРАБОТКА СПОСОБА УТИЛИЗАЦИИ ОТХОДОВ ГОРНО-ОБОГАТИТЕЛЬНЫХ КОМБИНАТОВ СОЗДАНИЕМ АКТИВНЫХ ФИЛЬТРУЮЩИХ ОБЕЗЖЕЛЕЗИВАЮЩИХ МАТЕРИАЛОВ
}

\section{Вадулина Надежда Вячеславовна',} momus7@mail.ru

\author{
Абдрахманов Наиль Хадитович', \\ anailx@mail.ru \\ Федосов Артем Васильевич', \\ fedsv-artem@rambler.ru \\ Бадртдинова Ильзида Илсуровна', \\ b.ilzida99@mail.ru \\ 1 Уфимский государственный нефтяной технический университет,
Россия, 450062, г. Уфа, ул. Космонавтов, 1.
}

\begin{abstract}
Актуальность исследования обусловлена тем, что техногенные образования в виде отвалов горно-обогатительных комбинатов являются причиной безвозвратных потерь природных сырьевых ресурсов, отчуждения земель из сельскохозяйственного оборота и загрязнения огромных территорий. Утилизация отходов горно-обогатительных и горнодобывающих предприятий считается одной из труднорешаемых задач Уральских регионов. Вследствие этого на сегодняшний день возникла необходимость в разработке технологии, которая смогла бы обеспечить эффективную переработку отходов горно-обогатительных комбинатов и вовлечение ценных сырьевых компонентов, до этого не утилизировавшихся отходов обогащения в производственный цикл. Одним из перспективных направлений на сегодняшний день является возможность использования отходов предприятий с получением товарного продукта.

Цель исследования: разработать способ утилизации отходов горно-обогатительных комбинатов, а именно осадков хвостохранилищ горно-обогатительных комбинатов, депонированием их в искусственные фильтрующие материалы в максимальном количестве.

объекты: химические и физико-механические характеристики разработанных материалов, качество сточной воды, зависимость качества очистки от состава искусственных фильтрующих материалов

Методы: анализ фильтрующих элементов на основе отходов горно-обогатительного комбината, на прочность и износоустойчивость методом истирания; исследование фильтрующей способности разработанного фильтрующего элемента, в состав которого в определенных соотношениях входят отходы горно-обогатительного производства, жидкое стекло и кремнефтористый натрий. Представлена таблица эффективности обезжелезивания сточной воды на данном материале и математические модели продолжительности процесса фильтрования и эффекта подщелачивания. Приведены методы удаления железа с помощью природных фильтрующих материалов и искусственных фильтрующих материалов, содержащих отходы хвостохранилищ и отвалов горно-обогатительных комбинатов.

Результаты. Приведен способ утилизации осадков хвостохранилищ горно-обогатительных комбинатов, определены факторы, влияющие на эффективную утилизацию отходов горно-обогатительных предприятий в фильтрующие материалы, исследованы физико-химические и фильтрационные свойства полученных материалов, определен состав фильтрующего элемента с максимальным содержанием отхода.
\end{abstract}

\section{Ключевые слова:}

Отходы горно-обогатительных комбинатов, утилизация отходов, шламовые отвалы, искусственные фильтрующие материалы, обезжелезивающий эффект.

\section{Введение}

Развитие промышленности приводит к увеличению объемов добычи полезных ископаемых. Добытое сырье, как правило, поступает на обогатительные фабрики, в результате после определенных операций образуются отходы, которые складируются в сложных гидротехнических сооружениях, называемых хвостохранилищами. Следовательно, хвостохранилища представляют собой сооружения, в которых скапливаются отходы горнодобывающей промышленности.

Хвосты - это отходы обогащения полезных ископаемых, в которых содержание ценного компонента ниже, по сравнению с исходным сырьем, вследствие того, что в них преобладают частицы пустой породы.
Твердая фаза хвостовой пульпы состоит из смеси минеральных частиц разного размера - от 3 мм до долей микрона. Состав частиц и их плотность зависят от минерального состава пород, вмещающих полезное ископаемое [1]. Полный химический состав отвальных хвостов представлен в табл. 1.

На территории Уральского региона на сегодняшний день накоплено более 15 миллиардов тонн отходов, которые представляют собой отвалы некондиционных руд, хвосто- и шламохранилищ, а также шламов нейтрализации кислых стоков [2]. Воздействие атмосферных осадков приводит к выщелачиванию из отвальных отходов тяжелых металлов с образованием растворимых соединений, которые впоследствии являются источниками за- 
грязнения подземных и поверхностных вод Башкортостана и регионов, находящихся в достаточно близких расстояниях. Образование отвалов также вызывает безвозвратные потери природных сырьевых ресурсов, отчуждение земли из сельскохозяйственного оборота и загрязнение почв. Вследствие достаточно значимых негативных последствий образовавшихся отвалов возникла необходимость в разработке технологии, которая обусловила бы эффективную утилизацию отходов обогащения и вовлечение их в цикл производства.

Таблица 1. Химический состав отвальных хвостов горнообогатительных комбинатов

Table 1. Chemical composition of dump tails of mining and processing works

\begin{tabular}{|c|c|}
\hline $\begin{array}{c}\text { Компонент } \\
\text { Component }\end{array}$ & $\begin{array}{c}\text { Содержание компонента в отходе } \\
\text { Content of the component in the waste, \% }\end{array}$ \\
\hline Железо/Iron & 38 \\
\hline Алюминий/Aluminum & 3 \\
\hline Кремний/Silicon & 8 \\
\hline Цинк/Zinc & 4 \\
\hline Медь/Copper & 0,86 \\
\hline Титан/Titanium & 0,31 \\
\hline Магний/Magnesium & 1,7 \\
\hline Сера/Sulfur & 35,93 \\
\hline Натрий/Sodium & 5,4 \\
\hline Кальций/Calcium & 2,8 \\
\hline Итого/Total & 100 \\
\hline
\end{tabular}

В настоящее время ПДК по железу в подземных водах Урала и Западной Сибири превышает допустимые нормы примерно в десятки раз [3]. Данный уровень показателя ПДК негативно сказывается на здоровье человека при использовании воды в хозяйственно-питьевых целях. Однако необходимо отметить, что для некоторых регионов подземные воды зачастую являются единственным источником водоснабжения, при этом они могут иметь высокое качество по другим показателям $[4,5]$.

Как следует из табл. 1, основным компонентом отвальных хвостов является железо, которое может быть использовано, например, при очистке сточных вод, т. к. является хорошим коагулянтом для содержащихся в них загрязнений. На основе этого свойства авторами предлагается использовать отходы горно-обогатительных предприятий для обезжелезивания природных и сточных вод. Удаление железа из сточных вод затрудняется тем, что стоки имеют низкие значения рН. В процессе нейтрализации вод, характеризующихся низким значением $\mathrm{pH}$, образуются рыхлые трудно утилизируемые осадки большого объема, которые складируются в отвалах.

Наиболее распространенным методом удаления железа является фильтрация на природных фильтрующих материалах. Для указанного метода необходимо дополнительное введение железосодержащих коагулянтов [6]. Создание искусственных фильтрующих материалов из отходов горного обогащения решит эту проблему.
При использовании искусственных фильтрующих материалов снижается отрицательное антропогенное воздействие ионов железа в сточных и природных водах на окружающую среду, поскольку по сравнению с природными фильтрующими материалами они задаются определенными свойствами и в их состав можно депонировать рыхлый и неподдающийся переработке осадок из отвалов горно-обогатительных комбинатов. Необходимо указать, что одной из труднорешаемых задач Уральских регионов считается утилизация отходов горно-обогатительных и горнодобывающих предприятий. Одним из перспективных направлений на сегодняшний день является возможность использования отходов предприятий с получением товарного продукта.

Разработка и использование технологий, которые обеспечивали бы снижение соединений железа как в сточных, так и в природных водах с помощью искусственных фильтрующих материалов на основе отходов обогащения, позволила бы решить ряд важнейших задач, таких как:

- утилизация отходов горно-обогатительного производства;

- предотвращение загрязнения окружающей природной среды токсичными компонентами;

- повышение эффективности удаления железа из сточных и природных вод, которые до этого не соответствовали требованиям, предъявляемым к составу и свойствам воды в водоемах рыбохозяйственного назначения.

\section{Предмет исследования}

Проведенный анализ различных литературных источников [7-12] привел к понятию того, что в настоящее время для очистки сточных и природных вод наиболее часто применяется метод фильтрования. Это вызвано тем, что данный метод считается наиболее простым и требует достаточно низких затрат, по сравнению с другими существующими методами. Недостатком фильтрования считается низкая эффективность при низких значениях $\mathrm{pH}$ и больших содержаниях железа в исходной воде. Следует отметить, что для данного метода требуется дополнительное введение кислорода или других окислителей. Активные фильтрующие материалы способны устранить или существенно снизить этот недостаток, однако их количество в природе ограничено и они не обладают всеми требуемыми свойствами.

Наличие растворенного железа в воде в основном зависит от рН воды. Процесс обезжелезивания происходит в том случае, при котором $\mathrm{pH}$ воды больше $\mathrm{pH}$ равновесного насыщения воды карбонатом железа при достаточно высокой щелочности среды или при рН больше 10,3, когда в осадок выпадает гидрат закиси железа. Кроме того, при значениях $\mathrm{pH}$ воды около 7 поверхность зерен загрузки имеет небольшой отрицательный электрокинетический потенциал, поэтому она обладает слабовыраженной сорбционной способностью по отношению к положительно заряженным ионам закис- 
ного железа. С возрастанием рН воды указанная сорбционная способность увеличивается. Величина $\mathrm{pH}$ влияет также и на способность фильтрующего материала удерживать железосодержащую пленку. При повышении рН эта способность возрастает. На поверхности фильтрующих материалов, не обладающих подщелачивающими свойствами, железосодержащая пленка не удерживается при промывке и выносится с промывной водой [13-16].

Большое внимание при окислении железа уделяется катализаторам. При контакте воды с оксидами марганца или с ранее выпавшим гидроксидом железа (III) скорость окисления железа (III) кислородом значительно возрастает.

Таким образом, возникает необходимость решения технической задачи, заключающейся в создании искусственного активного фильтрующего материала, обладающего подщелачивающими и каталитическими свойствами при невысокой размываемости фильтрующего материала [17].

\section{Методы исследования}

При создании искусственных фильтрующих материалов в качестве носителя выбран мел, который позволяет обогащать воду ионами Саи $\mathrm{CO}_{3}^{2+}$ и, в свою очередь, является весьма недорогим материалом. Жидкое стекло используется в качестве связующего и подщелачивающего компонента. А концентрат марганцевой руды и осадок сточных вод горно-обогатительного комбината вносятся в материал в качестве катализаторов.

Разработано три состава активных искусственных фильтрующих материалов: фильтрующий материал, обладающий подщелачивающими свойствами; фильтрующий материал, обладающий подщелачивающими и каталитическими свойствами, фильтрующий материал на основе отходов горно-обогатительного производства.

Рассмотрим исследование процесса удаления железа из сточных и природных вод на искусственных фильтрующих элементах на основе отхода горно-обогатительного комплекса.

Задача утилизации отходов горно-обогатительных комбинатов решается созданием фильтрующего материала на их основе. Отходы содержат большое количество железа, являющегося катализатором процесса обезжелезивания. Разработан следующий состав фильтруюшего материала: отход горно-обогатительного производства 28-48,25 мас. \%, жидкое стекло 50-65 мас. \%, кремнефтористый натрий 1,75-2,1 мас. \% (2,92-4,2 \% от жидкого стекла).

Необходимо указать, что эффект обезжелезивания и прочность фильтрующего материала зависят от связующего элемента, входящего в материал такого компонента, как жидкое стекло, и носителя, представленного ионами Са и $\mathrm{CO}_{3}^{2+}$. Жиидкое стекло показывает в результате гидролиза резко щелочную реакцию, а кремнефтористый натрий необходим для того, чтобы связать часть образующейся при этом щелочи, тем самым уменьшая высокое подщелачивание [18].
Эффективность обезжелезивания сточной воды на основе отходов горно-обогатительного производства представлена в табл. 2.

Для искусственных фильтрующих элементов на основе отходов горно-обогатительного производства эффективность обезжелезивания сточной воды выше по сравнению с фильтрующими элементами, обладающими подщелачивающими и каталитическими свойствами, и фильтрующими элементами, обладающими только подщелачивающими свойствами. Образцы выводились на промывку только в связи с увеличением потерь напора. Проскока железа в фильтрате не наблюдается.

Отход горно-обогатительного производства имеет многокомпонентный состав, влияющий на физикохимические процессы, происходящие при твердении материала, в фильтрующем материале увеличено содержание жидкого стекла, чем и вызван большой подщелачивающий эффект. Содержание кремнефтористого натрия в отходе уменьшено до допустимого минимума, с целью увеличения содержания в материале отхода производства. Увеличение содержания отхода более 40 \% вызывает разрушение материала и снижает его подщелачивающие свойства.

Из табл. 2 видно, что искусственный фильтрующий материал на основе отвальных хвостов подщелачивает воду до $\mathrm{pH}=9-11$. Такое значение $\mathrm{pH}$ превышает требуемое для окисления железа, но достаточно для образования гидроксида марганца. Установлен сопутствующий эффект использования данного искусственного фильтрующего материала для очистки воды от марганца, и разработана математическая модель для определения возможного количества депонирования отхода в состав фильтрующего материала вида уравнения регрессии:

$$
\begin{gathered}
Y=324,82+134 X_{1}-37,1 X_{2}- \\
-135,42 X_{1}^{2}+24,08 X_{2}^{2}-13,25 X_{1} X_{2},
\end{gathered}
$$

где $X_{1}$ - содержание отхода в образце, $\% ; X_{2}$ - скорость фильтрования, м/c.

\section{Заключение}

Одной из труднорешаемых задач Уральских регионов считается утилизация отходов горно-обогатительных и горнодобывающих предприятий. Стоит отметить, что одним из перспективных направлений на сегодняшний день является возможность использования отходов предприятий с получением товарного продукта.

Создание активного фильтрующего материала на основе отходов горно-обогатительного производства, обладающего высоким обезжелезивающим эффектом и способностью подщелачивания воды, решает эту проблему.

Решение задачи, заключающейся в утилизации отходов горно-обогатительных комплексов, было продемонстрировано в [19-20], где разрабатывается состав фильтрующего материала в определенных соотношениях компонентов, в которые входят отвальные хвосты горно-обогатительного производства, смесь жидкого стекла и кремнефтористого натрия. 
Таблица 2. Эффективность обезжелезивания на фильтрующем материале на основе отходов горно-обогатительного производства

Table 2. Effectiveness of deferrization on a filtering medium on the basis of a wastage of mining and processing production

\begin{tabular}{|c|c|c|c|c|c|c|}
\hline \multirow{3}{*}{$\begin{array}{l}\text { Состав образца } \\
\text { Sample composition } \\
\text { мac. \%/wt. \% }\end{array}$} & \multirow{3}{*}{$\begin{array}{l}\text { Cкорость } \\
\text { Velocity } \\
\text { M/4 } \\
\mathrm{m} / \mathrm{h}\end{array}$} & \multirow{3}{*}{$\begin{array}{l}\text { Расход } \\
\text { Rate } \\
\text { мл/мин } \\
\mathrm{ml} / \mathrm{min}\end{array}$} & \multicolumn{2}{|c|}{$\begin{array}{l}\text { Содержание железа } \\
\text { Iron content }\end{array}$} & \multicolumn{2}{|c|}{$\begin{array}{l}\mathrm{pH} \text { воды } \\
\text { Water pH }\end{array}$} \\
\hline & & & $\begin{array}{l}\text { Вход } \\
\text { Input }\end{array}$ & $\begin{array}{l}\text { Выход } \\
\text { Output }\end{array}$ & \multirow{2}{*}{$\begin{array}{l}\text { До очистки } \\
\text { Before cleaning }\end{array}$} & \multirow{2}{*}{$\begin{array}{l}\text { После очистки } \\
\text { After cleaning }\end{array}$} \\
\hline & & & \multicolumn{2}{|c|}{ Мг/л/mg/l } & & \\
\hline \multirow{4}{*}{$\begin{array}{l}\text { Отвальные хвосты/Dumptails - 48,25 } \\
\text { Жидкое стекло/Liquid glass - } 50 \\
\text { Кремнефтористый натрий/Fluorosilicate sodium - 1,75 }\end{array}$} & 23,4 & 60,00 & 2,5 & \multirow{4}{*}{$\begin{array}{l}\text { Отсутствие } \\
\text { Absence }\end{array}$} & 6,2 & 9,0 \\
\hline & 23,4 & 60,00 & 2,2 & & 4,8 & 8,8 \\
\hline & 23,4 & 60,00 & 2,0 & & 5,4 & 8,0 \\
\hline & 20,0 & 51,28 & 2,0 & & 5,2 & 7,8 \\
\hline \multicolumn{7}{|c|}{$\begin{array}{c}\text { Пропущено 84, } 87 \text { объема воды на один объем фильтрующего материала. Материал размывается } \\
84,87 \text { volumes of water per volume of filter media were filtered. The material is washed out }\end{array}$} \\
\hline \multirow{9}{*}{$\begin{array}{l}\text { Отвальные хвосты/Dumptails - } 40 \\
\text { Жидкое стекло/Liquid glass - 58,25 } \\
\text { Кремнефтористый натрий/Fluorosilicate sodium - 1,75 }\end{array}$} & 23,4 & 60,00 & 2,5 & \multirow{9}{*}{$\begin{array}{l}\text { Отсутствие } \\
\text { Absence }\end{array}$} & 6,2 & 10,0 \\
\hline & 23,4 & 60,00 & 2,2 & & 4,8 & 9,8 \\
\hline & 23,4 & 60,00 & 2,0 & & 5,4 & 9,8 \\
\hline & 20,0 & 51,28 & 2,0 & & 5,2 & 9,7 \\
\hline & 20,0 & 51,28 & 1,7 & & 5,7 & 9,6 \\
\hline & 20,0 & 51,28 & 1,8 & & 5,1 & 9,5 \\
\hline & 20,0 & 51,28 & 1,8 & & 5,1 & 9,5 \\
\hline & 16,2 & 30,00 & 2,2 & & 4,9 & 8,8 \\
\hline & 15,2 & 30 & 2,3 & & 5,8 & 8,2 \\
\hline \multicolumn{7}{|c|}{$\begin{array}{c}\text { Пропущено } 245 \text { объемов воды на один объем фильтрующего материала. } \\
\text { Материал выводился на промывку в связи с увеличением потерь напора } \\
245 \text { volumes of water per volume of filter media were filtered. The material was removed for washing due to increased head loss }\end{array}$} \\
\hline \multirow{9}{*}{$\begin{array}{l}\text { Отвальные хвосты/Dump tails - 30,9 } \\
\text { Жидкое стекло/Liquid glass - } 67 \\
\text { Кремнефтористый натрий/Fluorosilicate sodium - 2,123,4 }\end{array}$} & 23,4 & 60,00 & 2,5 & \multirow{9}{*}{$\begin{array}{l}\text { Отсутствие } \\
\text { Absence }\end{array}$} & 6,2 & 11,0 \\
\hline & 23,4 & 60,00 & 2,2 & & 4,8 & 11,0 \\
\hline & 23,4 & 60,00 & 2,0 & & 5,4 & 10,6 \\
\hline & 20,0 & 51,28 & 2,0 & & 5,2 & 10,4 \\
\hline & 20,0 & 51,28 & 1,7 & & 5,7 & 10,4 \\
\hline & 20,0 & 51,28 & 1,8 & & 5,1 & 10,3 \\
\hline & 20,0 & 51,28 & 1,8 & & 5,1 & 10,3 \\
\hline & 16,2 & 30,00 & 2,2 & & 4,9 & 9,8 \\
\hline & 16,2 & 30,00 & 2,3 & & 5,8 & 9,6 \\
\hline \multicolumn{7}{|c|}{$\begin{array}{r}\text { Пропущено } 245 \text { объемов воды на один объем фильтрующего материала. } \\
\text { Материал выводился на промывку в связи с увеличением потерь напора } \\
245 \text { volumes of water per volume of filter media were filtered. The material was removed for washing d }\end{array}$} \\
\hline \multirow{9}{*}{$\begin{array}{l}\text { Отвальные хвосты/Dump tails - } 33 \\
\text { Жидкое стекло/Liquid glass - } 65 \\
\text { Кремнефтористый натрий/Fluorosilicate sodium - } 2\end{array}$} & 23,4 & 60,00 & 2,5 & \multirow{9}{*}{$\begin{array}{l}\text { Отсутствие } \\
\text { Absence }\end{array}$} & 6,2 & 10,4 \\
\hline & 23,4 & 60,00 & 2,2 & & 4,8 & 10,3 \\
\hline & 23,4 & 60,00 & 2,0 & & 5,4 & 10,3 \\
\hline & 20,0 & 51,28 & 2,0 & & 5,2 & 10,2 \\
\hline & 20,0 & 51,28 & 1,7 & & 5,7 & 10,2 \\
\hline & 20,0 & 51,28 & 1,8 & & 5,1 & 10,2 \\
\hline & 20,0 & 51,28 & 1,8 & & 5,1 & 10,2 \\
\hline & 16,2 & 30,00 & 2,2 & & 4,9 & 9,6 \\
\hline & 16,2 & 30,00 & 2,3 & & 5,8 & 9,4 \\
\hline \multicolumn{7}{|c|}{$\begin{array}{c}\text { Пропущено } 245 \text { объемов воды на один объем фильтрующего материала. } \\
\text { Материал выводился на промывку в связи с увеличением потерь напора } \\
245 \text { volumes of water per volume of filter media were missed. The material was removed for washing in connection with increased head loss }\end{array}$} \\
\hline \multirow{9}{*}{$\begin{array}{l}\text { Отвальные хвосты/Dump tails - } 28 \\
\text { Жидкое стекло/Liquid glass }-70 \\
\text { Кремнефтористый натрий/Fluorosilicate sodium - } 2\end{array}$} & 23,4 & 60,00 & 2,5 & \multirow{9}{*}{$\begin{array}{l}\text { Отсутствие } \\
\text { Absence }\end{array}$} & 6,2 & 13,1 \\
\hline & 23,4 & 60,00 & 2,2 & & 4,8 & 12,9 \\
\hline & 23,4 & 60,00 & 2,0 & & 5,4 & 12,8 \\
\hline & 20,0 & 51,28 & 2,0 & & 5,2 & 12,6 \\
\hline & 20,0 & 51,28 & 1,7 & & 5,7 & 12,3 \\
\hline & 20,0 & 51,28 & 1,8 & & 5,1 & 12,2 \\
\hline & 20,0 & 51,28 & 1,8 & & 5,1 & 11,8 \\
\hline & 16,2 & 30,00 & 2,2 & & 4,9 & 11,4 \\
\hline & 16,2 & 30,00 & 2,3 & & 5,8 & 11,2 \\
\hline объел & $\begin{array}{ll}\text { оды на } \\
\text { f water }\end{array}$ & $\begin{array}{l}\text { uн объел } \\
\text { one volu }\end{array}$ & $\begin{array}{ll}\text { филь } \\
\text { eе of } f\end{array}$ & $\begin{array}{l}\text { ощего ма } \\
\text { media }\end{array}$ & & \\
\hline
\end{tabular}


Практическая значимость работы состоит в:

- утилизации отходов горно-обогатительных предприятий путем депонирования их в состав искусственных фильтрующих материалов;

- получении фильтрующих материалов с заданными свойствами;

- разработке и реализации в различных отраслях народного хозяйства технологии удаления железа из сточных и природных вод;

- снижении отрицательного антропогенного воздействия осадков сточных вод горно-обогатитель-

\section{СПИСОК ЛИТЕРАТУРЫ}

1. Аргимбаев К.Р. Промышленные отходы горного производства и их использование на примере Лебединского ГОКа // Молодой ученый. - 2011. - № 6.- С. 12-15.

2. A new approach for a special assessment of the working conditions at the production factors' impact through forecasting the occupational risks / N.Kh. Abdrakhmanov, N.V. Vadulina, A.V. Fedosov, S.M. Ryamova, E.Sh. Gaysin // Man in India. - 2017. V. 97 . - № 20. - P. 495-511.

3. Deliberate reorganization of the system of social relations in oil and gas companies in the period of changes in economics / L.M. Gaisina, V.V. Maier, N.Kh. Abdrakhmanov, E.A. Sultanova, M.L. Belonozhko // Espacios. - 2017. - V. 38. - № 48. - P. 12-24.

4. Heat absorption by heat-transfer agent in a flat plate solar collector/ M.M.Kunelbaev, E.Sh. Gaysin, V.V. Repin, M.M. Galiullin, K.N. Abdrakhmanova // International Journal of Pure and Applied Mathematics. - 2017. - V. 115. - № 3. - P. 518-530.

5. Principios y métodos de modelizaciónsinérgica del sistema de gestiónen las empresas del sector deópetr leo y gas / L.M. Gaisina, M.L. Belonozhko, N.A. Tkacheva, N.Kh. Abdrakhmanov, N.V. Grogulenko // Espacios. - 2017. - V. 38. - № 33. - P. 216-221.

6. Мочалова Л.А., Гриненко Д.А., Юрак В.В. Система обращения с твердыми коммунальными отходами: зарубежный и отечественный опыт // Известия Уральского государственного горного университета. - 2017. - № 3 (47). - С. 97-101.

7. Голик В.И., Разоренов Ю.И., Комащенко В.И. Сухие строительные смеси на основе отходов горного производства // Сухие строительные смеси. - 2017. - № 5. - С. 19-25.

8. Мелконян Р.Г. Экологические проблемы утилизации отходов горной промышленности для производства стекла и стройиндустрии // Вестник науки и образования Северо-Запада России. -2017 . - Т. 3. - № 1. - С. 58-69.

9. Research of a possibility of receiving sorbents for a sewage disposal from a wastage of coal preparation factory / S.L. Buyantuev, Y.Y. Stebenkova, A.B. Khmelev, A.S. Kondratenko, S.Y. Shishulkin // Journal of Physics: Conference Series. 2017. - V. 830. - № 1. - P. 012157.

10. Cherniak L., Varshavets P., Dorogan N. Development of a mineral binding material with elevated content of red mud // Technological audit and production reserves. - 2017. - V. 3. - № 3 (35). - P. $22-28$. ного производства путем депонирования этих осадков искусственных фильтрующих материалов;

- снижении отрицательного антропогенного воздействия соединений железа в сточных водах на живую природу за счет доведения качества стоков по железу до нормы;

- снижении экологической напряженности за счет вовлечения в водооборот природных вод, ранее не соответствующих требованиям, предъявляемым к составу и свойствам воды в водоемах рыбохозяйственного назначения.

11. Тимофеева Д.С., Кожухова В.И., Тимофеева А.С. Подготовка отходов процесса прямого восстановления железа для дальнейшего использования в металлургических переделах // Черная металлургия. - 2017. - № 1 (1405). - С. 94-98.

12. Повышение экономической эффективности горнодобывающих предприятий за счет вовлечения в эксплуатацию техногенных георесурсов / С.Е. Гавришев, С.Н. Корнилов, И.А. Пыталев, И.В. Гапонова // Горный журнал. - 2017. - № 12.- С. 46-51.

13. Шорохова А.В., Новичихин А.В. Комплексирование и математическое моделирование технологий переработки железорудных отходов обогатительных фабрик // Известия высших учебных заведений. Черная металлургия. - 2017. - Т. 60. - № 6. - С. 486-492.

14. Сердюк Ю.0., Цыбина А.В. Анализ общемировых тенденций развития технологий утилизации осадков сточных вод // Химия. Экология. Урбанистика. - 2017. - Т. 1. - С. 117-121.

15. Siadat S.A., Mokhtari J. The role of polyhexamethylene biguanide and silver nanoparticle interaction in the fabrication of novel antibacterial bio-fibers using silk wastage // Journal of Nano Research. - 2016. - V. 43. - P. 63-72.

16. Behaviours, thoughts and perceptions around mealtime insulin usage and wastage among people with type 1 and type 2 diabetes mellitus: a cross-sectional survey study / K. van Brunt, R. Pedersini, J. Rooney, S.M. Corrigan // Diabetes Research and Clinical Practice. - 2017. - V. 126. - P. 30-42.

17. Комащенко В.И., Воробьев Е.Д., Разоренов Ю.И. К концепции извлечения металлов при утилизации отходов обогащения руд // Известия Томского политехнического университета. Инжиниринг георесурсов. - 2017. - Т. 328. - № 10. - С. 18-24.

18. Heatabsorption by heat-transfer agent in a flatplatesolar collector / M.M. Kunelbayev, E.Sh. Gaysin, V.V. Repin, M.M. Galiullin, K.N. Abdrakhmanova // International Journal of Pure and Applied Mathematics. - 2017. - V. 115. - № 455. - P. 305-319.

19. Орешкин Д.В. Экологические проблемы комплексного освоения недр при масштабной утилизации техногенных минеральных ресурсов и отходов в производстве строительных материалов // Строительные материалы. - 2017. - № 8. - С. 55-63.

20. Галимов И.Р., Данильченко Л.М., Макавецкас А.Р. Комплексная утилизация горнопромышленных отходов // Рациональное освоение недр. - 2015. - № 5-6. - С. 108-115.

Поступила 11.04.2018 2.

\section{Информация об авторах}

Вадулина H.B., кандидат технических наук, доцент кафедры промышленной безопасности и охраны труда Уфимского государственного нефтяного технического университета.

Абдрахманов H.X., доктор технических наук, заведующий кафедрой промышленной безопасности и охраны труда Уфимского государственного нефтяного технического университета.

Федосов A.B., кандидат технических наук, доцент кафедры промышленной безопасности и охраны труда Уфимского государственного нефтяного технического университета.

Бадртдинова И.И., студент Уфимского государственного нефтяного технического университета. 


\title{
DEVELOPMENT OF A METHOD FOR UTILIZATION OF WASTE FROM MINING AND PROCESSING PLANTS BY CREATING ACTIVE FILTERING DEIRONING MATERIALS
}

\author{
Nadezhda V. Vadulina', \\ momus7@mail.ru
}

\author{
Nail Kh. Abdrakhmanov', \\ anailx@mail.ru \\ Artem V. Fedosov', \\ fedsv-artem@rambler.ru

\section{Ilzida I. Badrtdinova',} \\ b.ilzida99@mail.ru \\ 1 Ufa State Petroleum Technological University, \\ 1, Kosmonavtov street, Ufa, 450062, Russian Federation.
}

The relevance of researches is caused by the fact that technogenic formations in the form of dumps from mining and processing works are the reason of irrevocable losses of natural raw material resources, alienations of lands from an agricultural turn and pollution of huge territories. There is a need in developing a technology which could provide the efficient removal of iron from sewage without sludging neutralization and involving valuable input products, the wastage of enrichment, which have not been utilized yet, in a production cycle. A salvage of mining and processing and mining enterprises is considered as one of hardly solvable problems of the Ural region. One of the perspective directions today is a possibility of recovery of enterprises with obtaining marketable products.

The main aim of the research is to study the technology providing the efficient removal of iron ions from waste and natural water, to analyse a way of utilizing rainfall of tailings dams of mining and processing works.

The objects: chemical and physicomechanical characteristics of the developed materials, chemical tests of simulated, filtering mediums in various environments.

The methods: analysis of gauze elements on the basis of a wastage of mining and processing works; study of filtration capacity of the developed gauze element containing wastes of mining and processing production, liquid silica glass and sodium fluosilicate in particular ratios. The paper introduces the table of effectiveness of deferrization of waste water on this material and the methods of iron removal by means of natural filtering mediums and simulated filtering mediums.

The results. The paper introduces the factors influencing the efficient extraction of iron ions from waste and natural water. The authors have analyzed the simulated filtering mediums with the given properties for iron extraction from waste and natural water and studied physical and chemical and filtration characteristics of the materials obtained. The structure of filtering element with maximum waste was determined.

\section{Key words:}

Wastage of mining and processing works, recycling, slurry dumps, simulated filtering mediums, deferrizing effect.

\section{REFERENCES}

1. Argimbaev K.R. The industrial wastes of mining and their use on the example of Lebedinsky mining and processing works. The Young scientist, 2011, no. 6, pp. 12-15. In Rus.

2. Abdrakhmanov N.Kh., Vadulina N.V., Fedosov A.V., Ryamova S.M., Gaysin E.Sh. A new approach for a special assessment of the working conditions at the production factors' impact through forecasting the occupational risks. Man in India, 2017, vol. 97, no. 20 , pp. $495-511$.

3. Gaisina L.M., Maier V.V., Abdrakhmanov N.Kh., Sultanova E.A., Belonozhko M.L. Deliberate reorganization of the system of social relations in oil and gas companies in the period of changes in economics. Espacios, 2017, vol. 38, no. 48, pp. 12-24.

4. Kunelbaev M.M., Gaysin E.Sh., Repin V.V., Galiullin M.M., Abdrakhmanova K.N. Heat absorption by heat-transfer agent in a flat plate solar collector. International Journal of Pure and Applied Mathematics, 2017, vol. 115, no. 3, pp. 518-530.

5. Gaisina L.M., Belonozhko M.L., Tkacheva N.A., Abdrakhmanov N.Kh., Grogulenko N.V. Principios y métodos de modelizaciónsinérgica del sistema de gestiónen las empresas del sector de petróleo y gas. Espacios, 2017, vol. 38, no. 33, pp. 216-221.

6. Mochalova L.A., Grinenko D.A., Yurak V.V. The management of solid municipal waste: domestic and foreign experience. News of the Ural State Mining University, 2017, no. 3 (47), pp. 97-101. In Rus.

7. Golik V.I., Razorenov Yu.I., Komashchenko V.I. Dry construction mixtures based on mining waste. Dry construction mixtures, 2017, no. 5, pp. 19-25.

8. Melkonyan R.G. Environmental problems of waste disposal mining for glass and construction industry. Journal of Science and Education of North-West Russia, 2017, no. 3, pp. 58-69. In Rus.

9. Buyantuev S.L., Stebenkova Y.Y., Khmelev A.B., Kondratenko A.S., Shishulkin S.Y. Research of a possibility of receiving sorbents for a sewage disposal from a wastage of coal preparation factory. Journal of Physics: Conference Series, 2017, vol. 830, no. 1, pp. 012157.

10. Cherniak L., Varshavets P., Dorogan N. Development of a mineral binding material with elevated content of red mud. Technological audit and production reserves, 2017, vol. 3, no. 3 (35), pp. 22-28.

11. Timofeeva D.S., Kozhuhova V.I., Timofeeva A.S. The Preparation of the Wastes of the Direct Iron Reduction Process for the Further Utilization in the Metallurgical Processing. Ferrous Metallurgy, 2017, no. 1, pp. 94-98. In Rus.

12. Gavrishev S.E., Kornilov S.N., Pytalev I.A., Gaponova I.V. Increasing the economic efficiency of mining enterprises due to the in- 
volvement in the operation of man-made georesources. Mining Journal, 2017, no. 12, pp. 46-51. In Rus.

13. Shorohova A.V., Novichikhin A.V. Integrating and Mathematical Modeling of Processing Technologies for Iron Ore Waste at Beneficiation Plants. News of higher educational institutions Ferrous Metallurgy, 2017, no. 6, pp. 486-492.

14. Serdyuk Yu.0., Tsybina A.V. Analysis of global trends in the development of technologies for the disposal of sewage sludge. Chemistry. Ecology. Urbanism, 2017, no. 1, pp. 117-121.

15. Siadat S.A., Mokhtari J. The role of polyhexamethylene biguanide and silver nanoparticle interaction in the fabrication of novel antibacterial bio-fibers using silk wastage. Journal of Nano Research, 2016, vol. 43, pp. 63-72.

16. Van Brunt K., Pedersini R., Rooney J., Corrigan S.M. behaviours, thoughts and perceptions around mealtime insulin usage and wastage among people with type 1 and type 2 diabetes mellitus: a cross-sectional survey study. Diabetes Research and Clinical Practice, 2017, vol. 126, pp. 30-42.
17. Komashchenko V.I., Vorobev E.D., Razorenov Yu.I. Extraction of metals when recycling enrichment of ores. Bulletin of the Tomsk Polytechnic University. Geo Assets Engineering, 2017, no. 10, pp. 18-24. In Rus.

18. Kunelbayev M.M., Gaysin E.Sh., Repin V.V., Galiullin M.M., Abdrakhmanova K.N. Heat absorption by heat-transfer agent in a flat plate solar collector. International Journal of Pure and Applied Mathematics, 2017, vol. 115, no. 455, pp. 305-319.

19. Oreshkin D.V. Ecological problems of integrated development of the subsoil with large-scale utilization of technogenic mineral resources and wastes in the production of building materials. Construction Materials, 2017, no. 8, pp. 55-63.

20. Galimov I.R., Danilchenko L.M., Makavetskas A.R. Comprehensive utilization of mining waste. Rational development of the subsoil, 2015, no. 5-6, pp. 108-115.

Received: 11 April 2018.

\section{Information about the authors}

Nadezhda V. Vadulina, Cand. Sc., associate professor, Ufa State petroleum Technological University.

Nail Kh. Abdrakhmanov, Dr. Sc., professor, Ufa State Petroleum Technological University.

Artem V.Fedosov, Cand. Sc., associate professor, Ufa State Petroleum Technological University.

Ilzida I. Badrtdinova, student, Ufa State Petroleum Technological University. 